\title{
Selective Modification of Trp19 in $\beta$-Lactoglobulin by a New Diazo Fluorescence Probe
}

\author{
Zhijuan Bao, Shujuan Wang, Wen Shi, Suying Dong, and Huimin Ma* \\ [*] Beijing National Laboratory for Molecular Sciences, \\ Institute of Chemistry, Chinese Academy of Sciences, Beijing 100080 (China). \\ E-mail:mahm@iccas.ac.cn
}

Effects of Solvent, pH and Temperature on the Spectroscopic Properties of BDHD. Figure S1 shows the absorption spectra of BDHD in different solvents. The hydroxyl groups of BDHD may dissociate in base media (Figure S2). In addition, higher temperatures over $40^{\circ} \mathrm{C}$ may lead to the destruction of the probe (Figure S3).

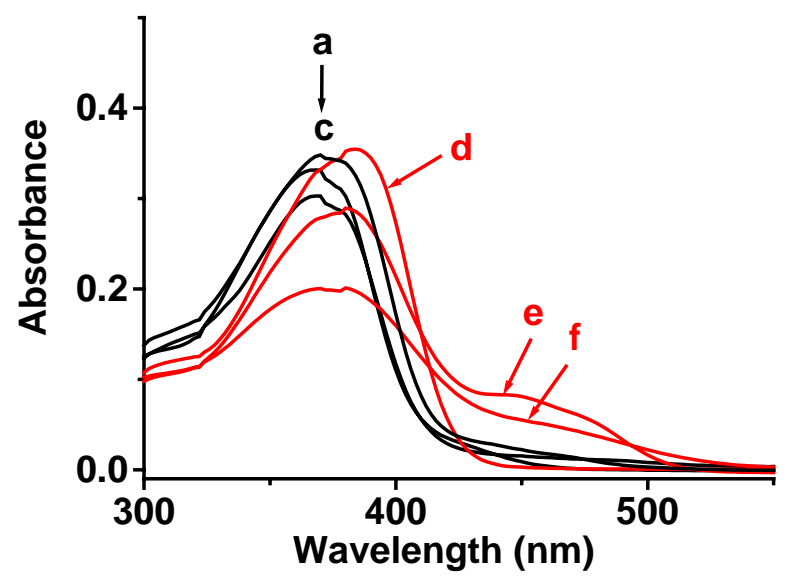

Supplementary Figure S1. Absorption spectra of BDHD $(10 \mu \mathrm{M})$ in different solvents: (a) toluene, (b) acetonitrile, (c) dichloromethane, (d) DMSO, (e) methanol, (f) phosphate buffer (pH 7.4). The spectra were measured at $25^{\circ} \mathrm{C}$ against the corresponding reagent blank (solvent). 


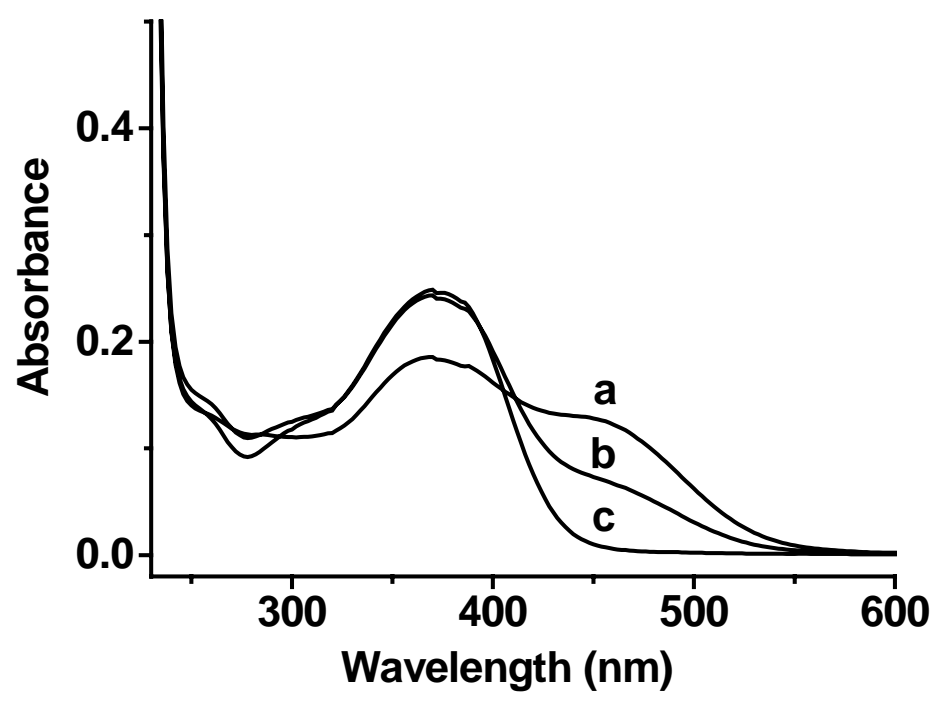

Supplementary Figure S2. Absorption spectral changes of BDHD $(10 \mu \mathrm{M})$ in $0.1 \mathrm{M}$ phosphate buffers with different $\mathrm{pH}$ values: (a) 8.0, (b) 7.4, and (c) 5.6. The spectra were measured at $25^{\circ} \mathrm{C}$ against the corresponding reagent blank (phosphate buffer).

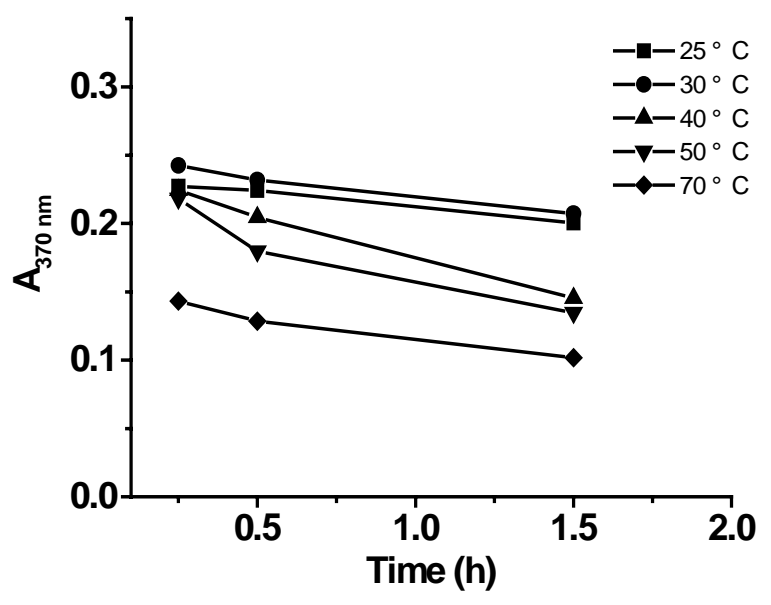

Supplementary Figure S3. The changes of absorbance at $370 \mathrm{~nm}$ of BDHD $(10 \mu \mathrm{M})$ in the phosphate buffer $(\mathrm{pH}$ 7.4) with different heating temperatures and times. 


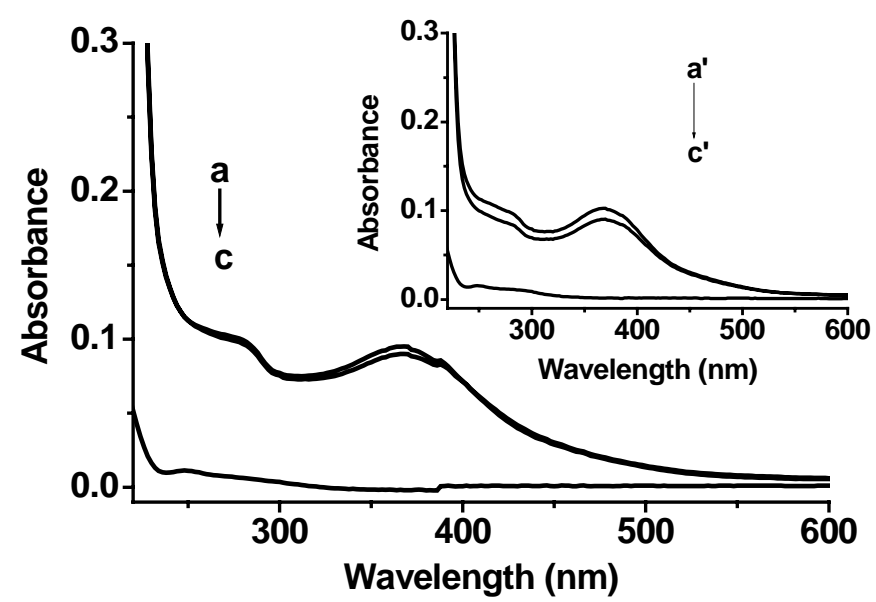

Supplementary Figure S4. Absorption spectral changes of BDHD $(8 \mu \mathrm{M})$ in $20 \%$ glycerol aqueous media ( $\mathrm{pH}$ 7.8): a) BDHD only, b) BDHD in the presence of $0.8 \mu \mathrm{M} \mathrm{Rh}{ }_{2}(\mathrm{OAc})_{4}, \mathrm{c}$ ) $\mathrm{Rh}_{2}(\mathrm{OAc})_{4}$ only. The inset shows the situation of the above solutions that had already been subjected to a labeling reaction at $0-4{ }^{\circ} \mathrm{C}$ for $24 \mathrm{~h}$ (the curves a'-c' correspond to the curves a-c).

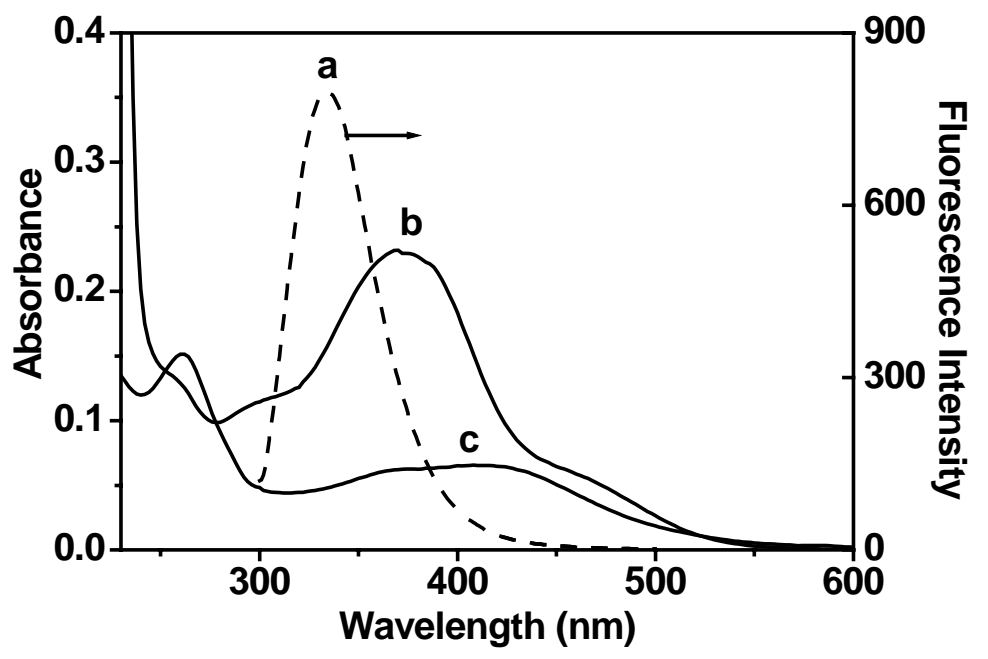

Supplementary Figure S5. Fluorescence emission spectrum of (a) native $\beta$-LG (5.5 $\mu \mathrm{M}, \lambda_{\mathrm{ex}}=$ $278 \mathrm{~nm})$, and absorption spectra of (b) BDHD $(10 \mu \mathrm{M})$ and (c) curcumin $(10 \mu \mathrm{M})$ in phosphate buffer (pH 7.4). 


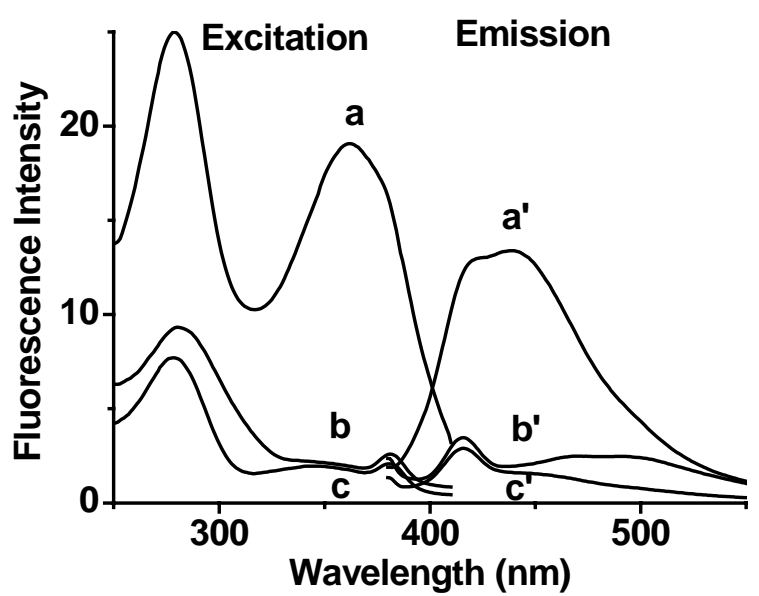

Supplementary Figure S6. Fluorescence spectra of the modified $\beta$-LG (curves a and a'), the simple mixture of $\beta$-LG and curcumin (curves b and b') and the simple mixture of $\beta$-LG and BDHD (curves c and c') in $0.1 \mathrm{M}$ of $\mathrm{Na}_{2} \mathrm{HPO}_{4}-\mathrm{NaH}_{2} \mathrm{PO}_{4}$ buffer (pH 7.4). Excitation spectra were recorded with $\lambda_{\mathrm{em}}=437 \mathrm{~nm}$ (the peaks at 278 and $362 \mathrm{~nm}$ in curve a come from $\beta$-LG and the curcumin moiety, respectively), and emission spectra recorded with $\lambda_{\mathrm{ex}}=362 \mathrm{~nm}$. The concentrations of $\beta$-LG, curcumin and BDHD were 5.5, 1.4 and $1.4 \mu \mathrm{M}$, respectively.

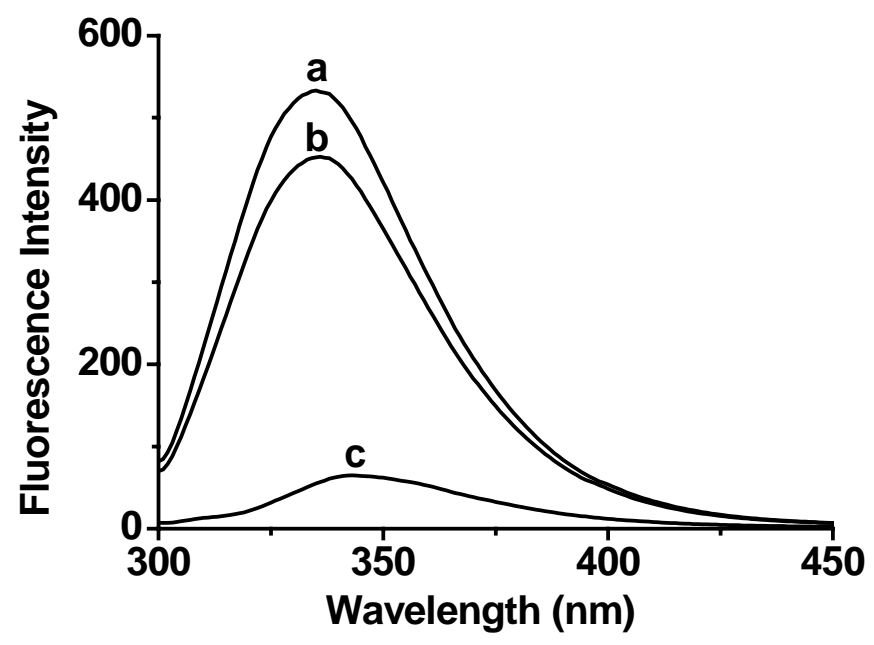

Supplementary Figure S7. Fluorescence spectra. (a) Native $\beta$-LG; (b) the simple mixture of $\beta$-LG and curcumin; and (c) curcumin only. The spectra were measured at $25{ }^{\circ} \mathrm{C}$ in $0.1 \mathrm{M}$ $\mathrm{Na}_{2} \mathrm{HPO}_{4}-\mathrm{NaH}_{2} \mathrm{PO}_{4}$ buffer ( $\mathrm{pH} 7.4$ ) with $278 \mathrm{~nm}$ as the excitation wavelength. The concentration of both $\beta$-LG and curcumin was $5 \mu \mathrm{M}$. 
Labeling of Tryptophan. The labeling of tryptophan as a model compound (Figure S8) was also attempted by using a similar procedure to that in the modification of $\beta$-LG. Briefly, $150 \mu \mathrm{L}$ of tryptophan $(10 \mathrm{mM}, 1.5 \mu \mathrm{mol})$ was added to $1.6 \mathrm{~mL}$ of a $20 \%(\mathrm{v} / \mathrm{v})$ glycerol solution ( $\mathrm{pH} 7.8$ ), followed by addition of $150 \mu \mathrm{L}$ of an aqueous solution of $\mathrm{Rh}_{2}(\mathrm{OAc})_{4}(1.8 \mathrm{mg} / \mathrm{mL}, 0.6 \mu \mathrm{mol})$. To the mixed reaction solution, $63 \mu \mathrm{L}$ of BDHD in DMSO $(9.6 \mathrm{mg} / \mathrm{mL}, 1.5 \mu \mathrm{mol})$ was then added. After incubated at $0-4{ }^{\circ} \mathrm{C}$ for $5 \mathrm{~h}$ with stirring, the reaction solution (the final $\mathrm{pH} 7.1$ ) was then subjected directly to ESI-MS analysis. As shown in Figure S9, besides the probe BDHD $(\mathrm{m} / \mathrm{z}$ 393 for $\left.[\mathrm{M}-\mathrm{H}]^{-}\right)$and BDHD's carbine form $\left(\mathrm{m} / \mathrm{z} 365\right.$ for $\left.[\mathrm{M}-\mathrm{H}]^{-}\right)$, the expected labeling product $\left(\mathrm{m} / \mathrm{z} 569\right.$ for $\left.[\mathrm{M}-\mathrm{H}]^{-}\right)$of tryptophan is indeed detected. Under the same condition, cysteine and tyrosine did not yield the corresponding labeled products, suggesting that the tryptophan labeling reaction is highly selective.

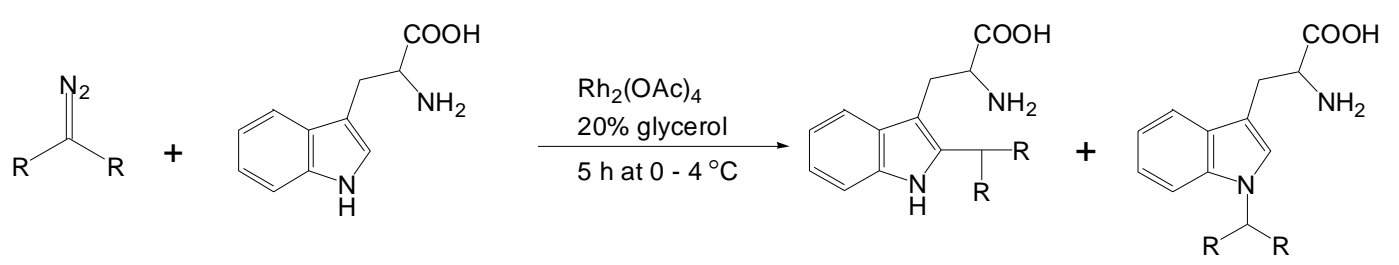

BDHD Tryptophan

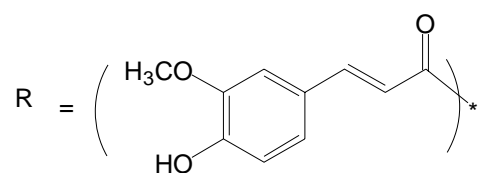

Supplementary Figure S8. Modification of tryptophan with BDHD.

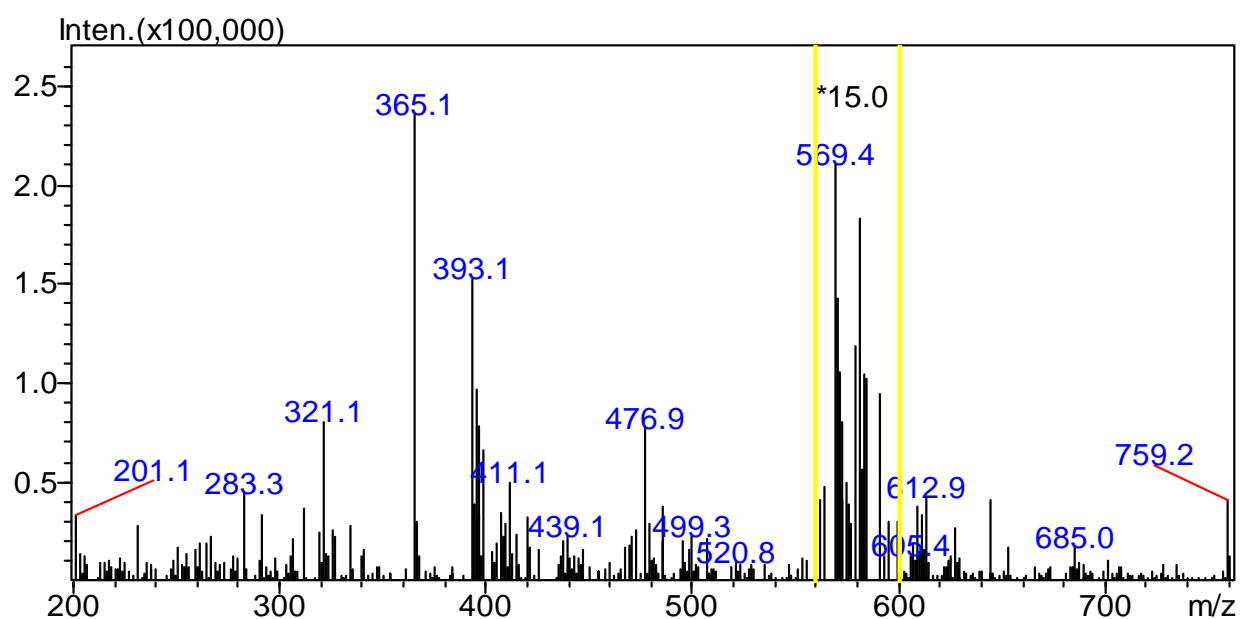

Supplementary Figure S9. Negative ESI mass spectrum of the reaction solution of tryptophan with BDHD. 